\title{
Psicologia Escolar e formação continuada de professores em gênero e sexualidade
}

\author{
Marivete Gesser \\ Leandro Castro Oltramari \\ Denise Cord \\ Adriano Henrique Nuernberg
}

\begin{abstract}
Resumo
Este artigo tem como objetivo identificar as contribuições teórico-metodológicas da Psicologia Escolar e áreas afins voltadas à formação de professores, para lidar com as questões relacionadas a gênero e sexualidade no contexto escolar. Para tanto, inicialmente se fará uma breve introdução, na qual serão identificados os documentos oficiais que norteiam a atuação dos profissionais da educação nas questões ligadas à sexualidade, com ênfase nos Parâmetros Curriculares Nacionais. Em seguida, buscar-se-á problematizar o lugar ocupado pelo professor nessas políticas educacionais e os limites que esse profissional pode encontrar quando se propõe a realizar um trabalho de educação sexual na escola. Por fim, serão apontados alguns pressupostos que, sem se pautar na racionalidade instrumental, possibilitam que ele desenvolva estratégias para lidar com as expressões de sexualidade em sala de aula, a partir de uma perspectiva norteada pelos princípios dos direitos humanos, alteridade e protagonismo social.
\end{abstract}

Palavras-chave: Psicologia escolar, formação de professores, sexualidade.

\section{School Psychology and Continuous Teacher Training in Gender and Sexuality}

\begin{abstract}
In this work we aim at identifying theoretical methodological contributions of school psychology to educators dealing with issues related to gender and sexuality within the school context. In a brief introduction we identify the official documents that guide education professionals in issues related to sexuality emphasizing on the National Curricular Parameters. After that, we discuss the place of teachers within educational policies and the barriers these professionals may face when they propose to carry out sexual education in school. Finally, we point out some assumptions that, without an instrumental rationality, may make possible for teachers to develop strategies to deal with expressions of sexuality in the classroom We argue that this should be done from the human rights 'perspective, considering alterity and social protagonism principles.
\end{abstract}

Keywords: School psychology, teacher education, sexuality.

\section{Psicología Escolar y formación continua de maestros en género y sexualidad}

\section{Resumen}

Este artículo tiene el objetivo de identificar las contribuciones teórico-metodológicas de la Psicología Escolar y áreas dedicadas a la formación de maestros en cuanto a temas relacionados a género y sexualidad en el contexto escolar. Inicialmente se hará una breve introducción en la cual se identificarán los documentos oficiales que orientan la actuación de los profesionales de la educación en temas de sexualidad con énfasis en los Parámetros Curriculares Nacionales. A continuación se buscará problematizar el lugar ocupado por el maestro en esas políticas educacionales y los límites que este profesional puede encontrar cuando se propone realizar un trabajo de educación sexual en la escuela. Finalmente se señalarán algunas presuposiciones que sin pautarse en la racionalidad instrumental posibilitan que el maestro desarrolle estrategias para tratar con las expresiones de sexualidad en aula a partir de una perspectiva orientada por principios de derechos humanos, alteridad y protagonismo social.

Palabras clave: Psicología Escolar, formación de profesores, sexualidad. 


\section{Introdução}

Hoje há um intenso debate sobre a possibilidade de a Psicologia Escolar contribuir com o trabalho de educação sexual nas escolas. Martinez (2010), em artigo teórico cujo objetivo é apontar de forma sintetizada o amplo leque de possibilidades de atuação do psicólogo nas escolas, destaca o trabalho voltado à educação sexual como uma forma de atuação profissional "tradicional", ou seja, como uma prática já reconhecida e consolidada no âmbito da atuação do psicólogo na escola.

Este artigo tem como objetivo identificar contribuições teórico-metodológicas da Psicologia Escolar e áreas afins voltadas à formação de educadores para lidar com as questões relacionadas a gênero e sexualidade no contexto escolar. Para tanto, far-se-á uma análise do caderno de Orientação Sexual ${ }^{1}$ que compõe os Parâmetros Curriculares Nacionais - PCN, com ênfase nas atribuições apontadas como sendo do educador.

Também serão apresentados alguns importantes conceitos para nortear o trabalho de formação de professores voltado à sexualidade na escola, sendo eles gênero, vulnerabilidade, direitos sexuais e direitos reprodutivos. No que se refere ao conceito de gênero e sua relação com a sexualidade, será destacada a necessidade de o educador perceber o impacto dos discursos referentes a essas questões no seu próprio processo de constituição como sujeito. Ademais, ressaltar-se-á a importância de que o professor perceba a construção histórica da sexualidade ocidental, tanto no que se refere ao discurso biomédico da sexualidade, quanto aos preceitos morais e religiosos que atuam nesse processo de constituição dos educadores como sujeitos de modo geral e em sua inserção no cotidiano escolar.

Por fim, propor-se-á um trabalho voltado à formação de professores que rompa com a cisão entre razão e emoção, pautada na racionalidade instrumental, e que abranja as dimensões do pensar, sentir e agir. Acredita-se que uma formação ético-política voltada à temática deve oferecer subsídios para que os educadores não apenas se instrumentalizem cognitivamente, mas também recriem o modo como lidam com sua sexualidade.

Embora no Brasil ainda não haja nenhuma lei que regulamente o trabalho voltado à educação sexual nas escolas, existem vários documentos que respaldam o desenvolvimento de intervenções nessa área, visando tanto à prevenção de doenças e promoção de saúde como também à garantia dos direitos humanos. Entre os documentos que apoiam a atuação profissional nesse campo, destacam-se: a) Parâmetros Curriculares Nacionais (Brasil, 1998); b) Es-

1Os PCN utilizam o termo "Orientação Sexual" para expressar o trabalho de educação sexual realizado nas escolas. Naquele documento, optou-se pelo emprego do referido termo por se defender que a educação sexual ocorre o tempo todo e para marcar que o trabalho realizado na escola deve ser o de orientar os alunos com os conhecimentos necessários para exercer sua sexualidade com autonomia. Todavia, como atualmente o termo orientação sexual é utilizado para nomear as diferentes formas de expressão da sexualidade, optou-se pelo termo educação sexual. tatuto da Criança e do Adolescente (Lei 8.069/90); c) Plano Nacional de Políticas para as Mulheres (Brasil, 2004a); d) Programa Brasil Sem Homofobia (Brasil, 2004b); e) Caderno Gênero e Diversidade Sexual na Escola; f) Programa de Saúde na Escola - PSE (Brasil, 2008).

O trabalho, que é voltado à garantia dos direitos sexuais e reprodutivos, legitimado pelos documentos acima apresentados, pode contribuir para a diminuição da vulnerabilidade social, conforme será discutido a seguir. Para tanto, é necessário compreender em que constituem as diretrizes do trabalho sobre sexualidade em sala de aula para os professores.

O caderno dos PCN que aborda a temática da educação sexual é considerado o marco indicador da legitimação da discussão do tema sexualidade na escola. Nele, sugere-se que o assunto seja trabalhado de forma transversal, em todas as disciplinas. Esse documento ainda ocupa, no cenário atual, o papel de "norteador" das atividades desenvolvidas no âmbito escolar.

O documento dos PCN dá ao professor um lugar de destaque no trabalho de educação sexual na escola (Leão, Ribeiro, \& Bedin, 2010). Cabe a ele reconhecer como legítimas e lícitas a busca do prazer e as curiosidades manifestadas acerca da sexualidade por crianças e jovens, uma vez que fazem parte do seu processo de desenvolvimento. Os PCN também apontam o educador como um profissional que deve se mostrar disponível para conversar sobre as questões referentes à sexualidade, de forma direta e esclarecedora. Ademais, cabe ao educador problematizar e debater sobre os diferentes tabus, preconceitos, crenças e atitudes existentes na sociedade, buscando se distanciar das opiniões e aspectos pessoais para empreender essa tarefa (Brasil, 1998).

Outro desafio mencionado pelos PCN no que se refere à postura do educador no trabalho de educação sexual é o de que é necessário refletir os valores democráticos e pluralistas, buscando, nas práticas, a equidade de gênero e a dignidade da pessoa humana. Trabalhar com o tema da sexualidade de modo a garantir o respeito à opinião de cada aluno, a participação de todos e a não discriminação das pessoas também é um desafio apontado à prática dos professores.

O lugar de destaque do professor no trabalho de educação sexual também aparece no $\mathrm{PSE}^{2}$. Segundo Mano, Gouveia e Schall (2009), o PSE constitui uma proposta com avanços efetivos no campo da educação em saúde na escola e na oferta de serviços à população adolescente. Este Programa, além de ampliar significativamente o debate sobre o tema, destacando a relevância das ações voltadas à promoção da saúde sexual e reprodutiva associada ao debate sobre gênero e orientação sexual, vem gerando soluções para dificuldades operacionais, como a criação de mecanismos de formação de professores e a elaboração de materiais educativos.

Percebe-se que o educador ocupa, na política educacional brasileira, um lugar central no trabalho de educação 2 O PSE é um programa interministerial (Ministério da Saúde e Ministério da Educação). 
sexual na escola. Ressalta-se, contudo, que, quando se trata de discutir como deve ser o processo de formação de professores para atuar com a temática da sexualidade no âmbito escolar, não se pode esquecer que os professores se constituíram sujeitos num contexto marcado pela hegemonia de concepções biomédicas ou morais e religiosas acerca de gênero e sexualidade (Yared, 2011). Diante disso, cabem alguns questionamentos: até que ponto se pode esperar que os educadores detenham todas as competências explicitadas pelos PCN como importantes no trabalho de educação sexual? Como esperar que o educador, que se constituiu sujeito a partir de valores morais, religiosos e/ou biomédicos, faça um trabalho de educação sexual problematizador e voltado à desconstrução de preconceitos de gênero? De que forma a Psicologia Escolar pode contribuir para que a formação dos professores capacite-os para lidarem com as questões relativas à sexualidade a partir de uma perspectiva ético-política? Ou seja: como contribuir com a desconstrução das significações de gênero e sexualidade opressoras das pessoas que não se encaixam no padrão heteronormativo, com a desnaturalização das violências, a ampliação da autonomia, a garantia dos direitos sexuais e reprodutivos e a diminuição da vulnerabilidade desses sujeitos?

Diversos estudos justificam a relevância de a Psicologia Escolar contribuir com subsídios teórico-metodológicos voltados à formação de professores para o trabalho de educação sexual. O estudo realizado por Ávila, Toneli e Andaló (2011) reafirmou a dificuldade dos professores, que se veem diante do desafio de inserir a questão da sexualidade em suas atividades docentes, sobretudo no tocante à tensão existente entre os pressupostos de direitos humanos que subjazem aos PCN e à perspectiva de muitos profissionais em manter esse tema no contexto da heteronormatividade e da moral religiosa. Conforme esse estudo, a produção das posturas docentes diante da sexualidade e dos gêneros não passa somente pelo crivo dos conteúdos escolares, das técnicas pedagógicas e das prescrições oficiais, inserindo-se na ordem da pessoalidade e da significação do tema no contexto das trajetórias profissionais.

Costa e Ribeiro (2011), partindo do pressuposto de que gênero e sexualidade devem ser objetos de estudo, pesquisa e intervenção na escola, realizaram um estudo com o objetivo de investigar as concepções de relações de gênero de um grupo de alunas do curso de Pedagogia que já atuavam na educação escolar como professoras. Os autores identificaram que os discursos sobre relações de gênero e sexualidade ainda encontram respaldo nas diferenças biológicas que foram apontadas pelas entrevistadas como características inerentes ao masculino e feminino, como também a heterossexualidade como única possibilidade de viver os desejos e as práticas sexuais.

Silva (2010) pesquisou o lugar que o tema "sexualidade" ocupa na formação inicial de professores em cursos de Pedagogia oferecidos por instituições formadoras de professores em uma capital da região norte do Brasil. Seu estudo concluiu que, além da insuficiente formação dos professores formadores, a ideologia que sustenta a indisponi- bilidade para lidar com questões sexuais e a idealização do ensino sobre sexualidade constituem entraves para tornar realizável o que proclamam fazer na prática.

Analisando o Projeto Pedagógico de um curso de formação em Pedagogia oferecido por uma universidade estadual brasileira, Leão (2009) constatou que praticamente não havia menção à sexualidade e orientação sexual na estrutura curricular do curso. Seu estudo, assim como o de Silva (2010), permitiu constatar que o tema "orientação sexual" acaba sendo abordado pelos docentes formadores de professores numa perspectiva espontaneísta e dependente da manifestação de interesse por parte dos alunos. Ambas as pesquisas apontam para evidências do pouco conhecimento dos docentes formadores de professores acerca da temática, a qual acaba sendo abordada numa perspectiva próxima ao senso comum ou utilizando-se de abordagens pontuais e não continuadas, como o recurso "palestra".

O estudo de Costa (2009) permite depreender as possíveis relações existentes entre a formação curricular obtida no curso de Pedagogia de uma universidade estadual brasileira, o conceito de sexualidade e as implicações dessa significação na prática pedagógica dos sujeitos pesquisados. A conclusão apresentada é a de que a ausência de disciplinas formadoras nessa perspectiva dificulta o desenvolvimento de uma prática pedagógica transformadora no cotidiano escolar. Declarando-se despreparadas do ponto de vista teórico-metodológico, as professoras tendem a desconsiderar as questões que surgem no cotidiano das salas de aula ou tratar da temática sob a perspectiva biológica ou do ensinamento de preceitos morais.

Em pesquisa realizada por Grossi, Cardozo, Oltramari e Fernandes (2009) sobre iniciação sexual e homofobia nas escolas de cinco regiões de Santa Catarina, identificou-se que a sexualidade não é percebida em sua plasticidade, e sim de forma estanque e imutável, sem possibilidade de transformação. Foi considerado indicador dessa significação o esforço demonstrado pelos educadores para contornar as expressões da sexualidade no contexto escolar, como namoros, "ficadas" ou situações indicadoras de homossexualidade, entendendo o exercício dessas possibilidades como não legítimas ao interior da escola.

Por essas situações, Campos (2004) aponta a necessidade de se pensar o processo de formação de professores como um espaço em que estes possam não somente ter contato, mas também refletir sobre os subsídios que ancoram as políticas educacionais voltadas à sexualidade. O autor destaca que, como os professores não apenas aplicam, mas reinterpretam as diretrizes curriculares que lhes são apresentadas a partir de suas próprias leituras de mundo, é necessário que haja uma reflexão coletiva sobre suas práticas, voltada ao desenvolvimento tanto do ensino quanto de si mesmos como profissionais.

Borges e Meyer (2008) afirmam que é na escola que podem surgir as piores situações de violência e exclusão a quem não pertence à sexualidade hegemônica. Diante disso, é fundamental que a escola tenha como projeto coletivo o respeito às diferenças e o rompimento com a segregação 
e com o preconceito no cotidiano escolar, e que isso seja pauta no processo de formação de professores, uma vez que lidar com as diferenças "exige sensibilidade diante de qualquer discriminação no trato cotidiano, evitando que os próprios docentes sejam a fonte de juízos, atitudes e preconceitos que desvalorizem a experiência de certos grupos sociais, culturais, étnicos ou religiosos" (Sacristán, citado por Campos, 2004, p. 730-731).

Louro (2007) também apresenta reflexões que apontam para a relevância de se realizar um trabalho de formação de professores em educação sexual. Referindo-se à discriminação vivenciada pelos sujeitos que diferem do padrão heterossexual, reproduzida no contexto escolar, a autora afirma que "a sexualidade ou as tensões em torno da sexualidade constituem-se numa questão que vale a pena colocar em primeiro plano" (p. 203).

Borges e Meyer (2008) realizaram uma pesquisa com educadoras da rede pública de ensino do município de Porto Alegre e demais municípios do estado do Rio Grande do Sul, as quais frequentaram um curso de formação de professores para atuar de forma transversal nas questões relacionadas à sexualidade, mais especificamente no combate à violência e à homofobia. O objetivo dessa pesquisa foi o de identificar o que os professores percebem como dificuldades e problemas relativos a questões vinculadas à sexualidade e à homofobia, e que efeitos o curso de formação produziu em suas atividades escolares. Um dos resultados identificados foi o de que as professoras, muito envolvidas com os temas da sexualidade e do respeito à diversidade, indicaram vivenciar um isolamento em seus espaços de atuação. Outros aspectos apontados como relevantes no estudo foram a constatação, por parte dos sujeitos, de que o tema sexualidade é considerado pelas escolas como menos importante do que os demais, e a de que o curso auxiliou-as, na medida em que deu legitimidade às ações que elas já realizavam.

Leão, Ribeiro e Bedin (2010) apontam a existência de entraves no trabalho com sexualidade, decorrentes dos preconceitos e discriminações e do desconhecimento dos professores sobre o assunto. Os autores apontam que a escola é um espaço privilegiado para um trabalho de conscientização que possibilite diminuir a vulnerabilidade através do seu papel de "educar, ensinar e formar" (p. 39). Para eles, a escola é um local apropriado, um espaço para que a intervenção educativa aconteça. Mas infelizmente existe uma falta de preparo dos professores e uma insistência para que eles trabalhem a temática na escola. Os autores ressaltam a importância de a formação dos professores ocorrer "em serviço" como um elemento favorecedor do aumento de sua eficácia. Essa modalidade, segundo eles, oportuniza a reflexão a partir das situações vivenciadas e possibilidades de intervenção com base nas realidades de seus próprios locais de trabalho.

Diante do exposto, destaca-se a relevância de a Psicologia Escolar contribuir com o trabalho de formação continuada de professores sob um ponto de vista ético e político de sexualidade, considerando esse tema na perspectiva dos direitos humanos. No próximo tópico, serão apresentados alguns aspectos relevantes para a realização do trabalho. Em seguida, serão propostas algumas contribuições para a atuação profissional do psicólogo nesse campo, além das últimas considerações.

\section{As determinações de gênero e a produção de vulnerabilidade(s): a negação dos direitos sexuais e reprodutivos}

As discussões acerca dos direitos humanos também devem nortear o trabalho do psicólogo escolar na formação de professores para as questões relacionadas a gênero e sexualidade. As conferências realizadas pela ONU - Organização das Nações Unidas - em Cairo e Pequim, na década de 90, preconizam o direito à vida, liberdade, saúde, educação, não discriminação e, inclusive, os direitos sexuais e reprodutivos na adolescência. Além disso, ressaltam que os países devem facilitar ao adolescente o acesso à informação sobre a sexualidade e reprodução, bem como implementar programas relativos à saúde sexual e reprodutiva que abranjam as temáticas planejamento familiar, métodos contraceptivos, aborto seguro nas circunstâncias em que a lei do país permite, aconselhamento e serviços obstetrícios adequados às necessidades de saúde (Ventura \& Corrêa, 2006).

A inserção dos direitos reprodutivos no âmbito dos direitos humanos é apontada como um grande avanço, pois não distingue o sexo/gênero da pessoa, sua religião, idade, raça/etnia ou grupo social a que pertence. Sendo assim, qualquer um deve ser reconhecido como sujeito de direitos nesse campo e deve ter asseguradas as condições para o exercício pleno desses direitos (Toneli, 2004).

Já em relação aos direitos sexuais, estes, de acordo com a definição adotada pela Organização Mundial de Saúde, seguem os direitos humanos que já são reconhecidos pelas leis e pelos documentos internacionais. Eles incluem o direito de todas as pessoas e repudiam qualquer forma de coerção, discriminação ou violência, devendo ser protegidos e respeitados (Toneli, 2004).

Quando há uma negação de direitos sexuais e reprodutivos legitimada pela escola, esta acaba operando como produtora de vulnerabilidades. Para continuar o debate aqui indicado, com vistas à proposição de uma modalidade de formação de professores ancorada na discussão sobre sexualidade não reduzida à dimensão reprodutiva ou mesmo curativa, cabe contextualizar o entendimento que temos acerca do conceito de vulnerabilidade e a relação entre esse conceito e o papel social da escola frente a essa questão.

Para Munoz Sanchez e Bertolozzi (2007), a vulnerabilidade supera a condição individual de risco, pois abrange aspectos de contexto e coletivamente vividos que fazem com que as pessoas estejam sujeitas ao acometimento de doenças ou sofrimentos relacionados à sua saúde. Além disso, esse conceito traz em si uma preocupação com os recursos disponíveis às pessoas para enfrentar tal condição, tanto do ponto de vista político quanto social. 
Conforme apontam Villela e Doreto (2006), nas sociedades contemporâneas, a escola tem se mostrado como um importante espaço voltado à aquisição de habilidades cognitivas e sociais por crianças e jovens, contribuindo para os processos de recriação de si e do mundo. Destarte, as autoras destacam que "jovens fora da escola têm menos chances de reinterpretar as mensagens pejorativas relacionadas às ideias de pobreza, negritude e feminilidade, o que interfere no modo como será exercida a sua sexualidade" (Villela \& Doreto, 2006, p. 2.469).

No que se refere a gênero, cabe aqui ressaltar que a compreensão desse conceito como uma categoria de análise aponta para uma nova maneira de interpretar a relação entre homens e mulheres de uma forma não hierárquica e não dicotomizada, mas socialmente atribuída e construtora de respostas e expectativas sociais conforme os sexos biológicos (Scott, 1995). Além disso, assim como aponta Connell (1990), existe, desde as ideologias do patriarcado, uma reprodução social que tenta manter os princípios da hierarquia, da subordinação e hierarquização de gênero a partir do sexo. Destaca-se que a construção do gênero (normas de masculinidade e de feminilidade) e o processo de produção e (re)produção delas no contexto escolar, bem como a imbricação de gênero com outros determinantes como os de classe social, religiosidade, raça e deficiência, podem amplificar as desigualdades e gerar vulnerabilidades. Defende-se, neste ensaio, que a discussão se torna fundamental em processos de formação do professor, uma vez que seu papel profissional é constituído em um contexto social e político no qual sua formação influenciará a formação que possibilitará aos outros.

\section{Por uma formação de professores ético-política relacionada a gênero e sexualidade}

Neste momento, propor-se-á que o processo de formação de professores nas questões relacionadas a gênero e sexualidade deve ser pautado em uma perspectiva ético-política de sexualidade e de educação inclusiva. Tal perspectiva, além das características já apresentadas, aponta para o rompimento das cisões ${ }^{3}$ entre objetividade e subjetividade, razão e emoção (Leite \& Tassoni, 2002; Molon, 2003; Sawaia, 2005), subvertendo a racionalidade instrumental que reduz o sujeito professor à dimensão da cognição e opera com a expectativa de que os conhecimentos disponibilizados sejam assimilados por eles e transformados em ações "corretas" às expressões relacionadas à sexualidade na sala de aula. Ademais, ao se referenciar à perspectiva inclusiva da educação (Figueiró, 2009), reafirmam-se os princípios de

3 A tradicional visão dualista do homem como corpo/mente, matéria/ espírito, afeto/cognição, presente na trajetória do pensamento e do conhecimento há muitos séculos, tem se manifestado em estudos sobre o comportamento a partir de uma visão que cinde racional e emocional, pressupondo-se, geralmente, que o primeiro deveria dominar o segundo, impedindo uma compreensão da totalidade do ser humano (Leite \& Tassoni, 2002). igualdade na diferença e o acolhimento de todas as manifestações relativas à sexualidade.

Ressalta-se que uma formação ético-política voltada à temática "sexualidade" deve contribuir para que os educadores não apenas se instrumentalizem cognitivamente, mas também recriem o modo como lidam com as expressões da sexualidade que emergem no cotidiano escolar. Além disso, deve-se promover a apropriação crítica da construção histórica das desigualdades de gênero e da heteronormatividade, bem como a desconstrução de modelos reducionistas de compreensão do comportamento sexual que acabam por desconsiderar importantes dimensões, como a afetiva e a de gênero.

Para aprofundar a discussão referente à perspectiva ética e política, aponta-se que o trabalho de formação de professores deve possibilitar a construção de formas potencializadoras de pensar, sentir e agir em relação à sexualidade, sendo essas subversivas às normas e aos preceitos jurídicos, religiosos, morais ou educacionais que discriminam sujeitos, porque "o seu modo de ser homem ou de ser mulher, suas formas de expressar desejos e prazeres não correspondem àquelas nomeadas como 'normais'" (Louro, 2007, p. 201).

Um dos elementos norteadores da formação de professores para o trabalho com educação e sexualidade deve ser o de sensibilizá-los para as questões relativas aos direitos sexuais e reprodutivos, que são atualmente caracterizados como direitos humanos (Toneli, 2004). Sen (2010), ganhador do Prêmio Nobel de Economia e um dos mais importantes teóricos de justiça na atualidade, aponta que a discussão a respeito dos direitos humanos não deve se fundamentar apenas em um marco legislativo de proteção a direitos, mas principalmente em uma ética social sobre o justo. Destarte, a partir das considerações do autor, a garantia dos direitos humanos é um compromisso e uma responsabilidade de cada cidadão. Diante disto, considerando que a escola tem sido um importante espaço para o desenvolvimento de ações voltadas à garantia dos direitos sexuais e reprodutivos (Rios, Pimenta, Brito, Terto Jr., \& Parker, 2002; Villela \& Doreto, 2006), cabe preparar seus atores sociais para intervirem de acordo com uma perspectiva de direitos humanos.

Reconhecer direitos humanos não é insistir para que todas as pessoas, em todos os lugares, levantem-se a fim de ajudar a prevenir toda violação de todo direito humano, o que quer que aconteça. É, na verdade, reconhecer que, se alguém tem a possibilidade plausível de fazer algo eficaz para prevenir a violação de um direito, então tal pessoa tem a obrigação de considerar fazer exatamente isso. É possível que outras obrigações ou preocupações se sobreponham à razão para tal ação específica, mas essa razão não pode simplesmente ser posta de lado por "não ser da minha conta". Obrigações fracamente especificadas não devem ser confundidas com a ausência de obrigações. (Sen, 2010, p. 45 , grifo nosso).

Portanto, a partir das considerações de Sen (2010), pode-se afirmar que o trabalho de formação de professores para atuarem com as questões relativas à sexualidade deve 
abranger a questão dos diretos sexuais e reprodutivos, caracterizados como direitos humanos. Assim, esse trabalho deve problematizar temas como desigualdades de gênero, violência sexual e homofobia, além de proporcionar informações necessárias à diminuição da vulnerabilidade dos jovens, a partir de elementos das suas próprias sexualidades.

Para que o trabalho de formação dos professores tenha êxito, também é necessário que ele seja desenvolvido a posteriori, ou seja, com base nas dificuldades enfrentadas no cotidiano da sala de aula e demais espaços da escola, nem sempre claras/perceptíveis para eles. Para tanto, é importante romper com as propostas "preestabelecidas", que utilizam estratégias homogêneas e que são voltadas à formação em massa, e centrar as estratégias com base na escuta dos professores. É fundamental saber o que os professores pensam sobre a educação, sobre as expressões de sexualidade que ocorrem cotidianamente na escola e sobre o modo como lidam com essas expressões. Essa maneira de conceber a formação de professores, também proposta por Costa e Ribeiro (2011), faz oposição ao modo "atacadista" e "utilitarista", ainda muito frequente na contemporaneidade. Altenfelder (2006), em pesquisa realizada com a finalidade de avaliar o processo de formação de professores promovido pela Secretaria de Educação de um município da Grande São Paulo, identificou que os encontros são elaborados a priori, ou seja, sem a realização de um trabalho que identifique as dificuldades vivenciadas no cotidiano da sala de aula e sem a devida participação dos professores em seu planejamento. A autora destaca, a partir do relato das professoras entrevistadas, que da participação nesses encontros emergem sentimentos como os de "sentir-se perdida", de "vazio", bem como a dificuldade de aplicar os conhecimentos lá apresentados na prática. Ou seja,

a teoria parece percebida como algo muito abstrato, bastante distante da realidade vivida em sala de aula. Por não irem ao encontro das necessidades dos professores e não oferecerem subsídio para resolver as dificuldades e os impasses da prática, os momentos de reflexão teórica acabam sendo desvalorizados. (Altenfelder, 2006. p. 48).

Outro aspecto importante a ser considerado no trabalho de formação de professores refere-se à construção de espaços de escuta de suas práticas, sua concepção de trabalho e sua inserção na instituição. Nesses espaços, devem ser potencializadas a reflexão, a discussão e a criação de formas de proceder em relação às dificuldades vivenciadas no cotidiano escolar, de modo que os professores possam construir, juntos, estratégias de enfrentamento das dificuldades cotidianas (Aguiar, 2000; Altenfender, 2006). Acredita-se que os espaços voltados à intersubjetividade possam favorecer o desenvolvimento da sensibilidade, da imaginação e da criação, visando ao desenvolvimento de novas formas de pensar, sentir e agir no exercício docente (Almeida, 2002; Molon, 2006; Zanella \& Molon, 2007). Destaca-se ainda que tais espaços podem contribuir para o professor se apropriar de sua história e, nesse processo, reconstruir-se, reinventar- -se e agir em sua vida e na sala de aula (Aguiar, 2000; Altenfender, 2006; Sawaya, 2002).

Também é importante que o psicólogo, ao longo da formação de professores em uma perspectiva ético-política de sexualidade, seja um mediador nos processos de apropriação e reflexão crítica sobre os principais discursos constituintes da sexualidade na contemporaneidade, tornando visíveis as implicações destes no modo como os professores lidam com as expressões de sexualidade no cotidiano. Para tanto, os professores devem contar com um espaço em que possam se apropriar criticamente dos mitos, tabus e preconceitos relacionados à sexualidade, presentes no contexto histórico-cultural no qual eles se constituíram e que medeiam seus pensamentos, sentimentos e ações relacionados à temática no cotidiano escolar (Ávila, 2011). Destarte, faz-se mister contribuir com a subversão dos discursos hegemônicos que estabelecem um padrão de sexualidade e apontam para ações que desqualificam, negam e marginalizam diferentes modos de amar e de sentir prazer.

\section{Considerações finais}

Face ao exposto, cabe ressaltar que a Psicologia Escolar pode contribuir com o trabalho de formação dos professores no campo da sexualidade, oportunizando que estes passem por um processo de "reflexão pessoal sobre o tema e também por uma revisão dos próprios valores, dos próprios sentimentos, dos possíveis tabus e preconceitos existentes a esse respeito" (Figueiró, 2009, p. 166).

Considerando a dificuldade de os professores lidarem com expressões e sexualidades que diferem dos padrões tradicionais, destaca-se a necessidade de o processo de formação de professores ser norteado por uma compreensão de que a sexualidade não deve ser entendida como dissociada da vida. Isso implica que o comportamento sexual dos jovens deve ser compreendido a partir do cotidiano deles, com os atravessamentos de gênero, raça, classe social, religiosidade, perspectivas de vida. O professor deve ser instrumentalizado a desenvolver estratégias de educação sexual a partir dos aspectos acima citados e pautar suas intervenções com base nas realidades dos jovens. Para tanto, o desenvolvimento de uma escuta ativa, livre dos preconceitos comumente associados à adolescência e juventude, e capaz de encará-los como sujeitos com direitos sexuais e reprodutivos, é condição sine qua non para uma efetiva incorporação dos ideais preconizados nos PCN.

Diante das diferentes contribuições apresentadas, propõe-se que a Psicologia Escolar participe da formação de professores em sexualidade por meio do resgate da constituição dos professores como sujeitos, mediando processos nos quais possam se apropriar de suas histórias e reconstruir seu fazer como devir (Gesser \& Nuernberg, 2011). Para tanto, os trabalhos de formação de professores devem enfocar não apenas o aspecto racional, mas também ampliar a sensibilidade, a imaginação e a criação (Molon, 2006). Eles devem sair do campo coercitivo, dos padrões estáticos 
fundamentados em concepções normatizadoras de gênero e sexualidade, para se abrir para o campo da ética e dos diretos humanos.

Entendemos que essa proposta possibilita dar ênfase à totalidade de dimensões constitutivas do sujeito, contribuindo com a superação da racionalidade instrumental presente nas ciências sociais e humanas, que cinde o cognitivo e o afetivo, o objetivo e o subjetivo (Leite \& Tassoni, 2002; Molon, 2003; Sawaia, 2009). Por fim, pode contribuir para a emergência de novas abordagens da Psicologia Escolar e Educacional à temática da sexualidade no processo de formação de professores a partir de um posicionamento ético e político.

\section{Referências}

Aguiar, W. M. J. de. (2000). Professor e Educação: Realidades em Movimento. Em E. de Tanamachi, M. L. da Rocha \& M. Proença (Orgs.), Psicologia e educação: desafios teórico-práticos (pp. 169184). São Paulo: Casa do Psicólogo.

Almeida, L. R. de. (2002). Diretrizes para a formação de professores: uma releitura. Em: L. R. de Almeida \& V. M. N. de S. Placo, As relações interpessoais na formação de professores (pp. 21-33). São Paulo: Loyola.

Altenfender, A. H. (2006). Formação continuada: os sentidos atribuídos na voz do professor. Em W. M. J. de Aguiar (Org.), Sentidos e significados do professor na perspectiva sócio-histórica: Relatos de pesquisa (pp. 41-58). São Paulo: Casa do Psicólogo.

Avila, A. H., Toneli, M. J. F., \& Andaló, C. S. de A. (2011). Professores/ as diante da sexualidade-gênero no cotidiano escolar. Psicol. estud., 16(2), 289-298.

Borges, Z. N., \& Meyer, D. E. (2008). Limites e possibilidades de uma ação educativa na redução da vulnerabilidade à violência e à homofobia. Aval. pol. públ. Educ. 16(58), 59-76.

Brasil sem Homofobia. (2004b). Diretrizes do programa de combate à violência e à discriminação contra GLTB e promoção da cidadania homossexual. Brasília, DF: Ministério da Saúde. Conselho Nacional de Combate à discriminação. Recuperado: 15 mai 2010. Disponível: http://www.mj.gov.br/sedh/documentos/004_1_3.pdf

Campos, A. C. de O. (2004). Pluralidade cultural e inclusão na formação de professoras e professores: gênero, sexualidade, raça, educação especial, educação indígena, educação de jovens e adultos. Cad. Pesqu. 34(123), 730-734.

Connell, R.W. (1990). Como teorizar o patriarcado. Em E. M. T. Lopes \& G. L. Louro, Educação e Realidade 16(2), 85-93.

Costa, A. P. (2009). As concepções de sexualidade de um grupo de alunas do curso de Pedagogia: uma análise a partir do recorte de gênero. Dissertação de Mestrado, Universidade Estadual Paulista, Araraquara, São Paulo.
Costa, A. P., \& Ribeiro, P. R. M. (2011). Ser professora, ser mulher: um estudo sobre concepções de gênero e sexualidade para um grupo de alunas de pedagogia. Estudos Feministas. 19(2), 475-489.

Figueiró, M. N. D. (2009). Educação Sexual: como ensinar no espaço da escola. Em: M. N. D. Figueiró (Org.), Educação sexual: múltiplos temas, compromissos comuns. Londrina, PR: UEL.

Gesser, M., \& Nuernberg, A. H. (2011). Contribuições da psicologia histórico-cultural ao processo de formação continuada de professores (Trabalho Completo). Anais do Congresso Nacional de Psicologia Escolar e Educacional (pp. 1-13). Maringá, PR.

Grossi, M. P., Cardozo, F., Oltramari, L. C., \& Fernandes, F. B. M. (2009). Conclusão: Estratégias para melhorar os serviços de prevenção na escola. Em M. P. Grossi, F. Cardozo \& F. B. M. Fernandes (Orgs.), Representações de Iniciação Sexual e Homossexualidades em Escolas do Ensino Público de Santa Catarina: Relatório de Pesquisa (pp. 138-140). Brasília, DF: Ministério da Saúde.

Leão, A. M. C. (2009). Estudo analítico-descritivo do curso de Pedagogia da Unesp-Araraquara nas temáticas de sexualidade e orientação sexual na formação de seus alunos. Tese de Doutorado, Universidade Estadual Paulista, Araraquara, São Paulo.

Leão, A. M. C., Ribeiro, P. R. M., \& Bedin, R. C. (2010). Sexualidade e orientação sexual na escola em foco: algumas reflexões sobre a formação dos professores. Linhas. 11, 36-52.

Lei 8.069/1990. (1990). Estatuto da Criança e do Adolescente. Secretaria Especial dos Direitos Humanos; Ministério da Educação, Assessoria de Comunicação Social. Brasília: MEC, ACS.

Leite, S. A. da S., \& Tassoni, E. C. M. (2002). A afetividade em sala de aula: as condições de ensino e a mediação do professor. Em R. G. Azzi \& A. M. de A. Sadalla (Orgs.), Psicologia e formação docente: desafios e conversas. São Paulo, Casa do Psicólogo.

Louro, G. L. (2007). Gênero, sexualidade e educação: das afinidades políticas às tensões teórico-metodológicas. Educ. rev. 46, 201218.

Mano, S. M. F., Gouveia, F. C., \& Schall, V. T. (2009). "Amor e sexo: mitos, verdades e fantasias": jovens avaliam potencial de material multimídia educativo em saúde. Ciênc. educ., 15(3) 647-658.

Martinez, A. M. (2010). O que pode fazer o psicólogo na escola. Em Aberto 23(83), 39-56.

Molon, S. I. (2003). Subjetividade e constituição do sujeito em Vygotsky. Petrópolis, RJ: Vozes.

Molon, S. I. (2006). Subjetividade, sujeito e atividade criadora: questões para a formação continuada de educadores(as) na abordagem sócio-histórica. Em: S. Z. da Ros, K. Maheirie \& A. V. Zanella (Orgs.), Relações estéticas, atividade criadora e 
imaginação: sujeitos e (em) experiência (pp. 95-114), Florianópolis, SC: NUP/CED/UFSC.

Munoz Sanchez, A. I., \& Bertolozzi, M. R. (2007). Pode o conceito de vulnerabilidade apoiar a construção do conhecimento em Saúde Coletiva? Ciên. saúde coletiva, 12(2), 319-324.

Parâmetros Curriculares Nacionais: terceiro e quarto ciclos do ensino fundamental. (1998). Estabelece os parâmetros curriculares nacionais - temas transversais. Brasília, DF: Ministério da Educação e do Desporto. Secretaria de Educação Fundamental.

Plano Nacional de Políticas para as Mulheres. (2004a). Brasília, DF: Secretaria Especial de Políticas para as Mulheres.

Programa Nacional de DST e AIDS. (2008). Diretrizes para a Implantação do Projeto Saúde e Prevenção nas Escolas. Ministério da Saúde. Secretaria de Vigilância em Saúde. Brasília, DF: Ministério da Saúde.

Rios, L. F., Pimenta, C., Brito, I., Terto Júnior, V., \& Parker, R. (2002). Rumo à adultez: oportunidades e barreiras para a saúde sexual dos jovens brasileiros. Cadernos CEDES 22(57), 45-61.

Sawaia, B. B. (2005). O sofrimento ético-político como categoria de análise da dialética exclusão/inclusão Em B. B. Sawaia (Org.), As artimanhas da exclusão: análise psicossocial e ética da desigualdade social (4a ed., pp. 97-118). Petrópolis, RJ: Vozes.

Sawaia, B. B. (2009). Psicologia e desigualdade social: uma reflexão sobre liberdade e transformação social. Psicologia \& Sociedade; 21(3), 364-372.

Sawaya, S. M. (2002). Novas perspectivas sobre o sucesso e o fracasso escolar. Em M. K. de Oliveira, D. T. R. Souza \& T. C.
Rego (Orgs.). Em Psicologia, Educação e temáticas da vida contemporânea (pp. 197-213). São Paulo: Moderna.

Scott, J. (1995). Gênero: uma categoria útil de análise histórica. Educação e Realidade. 20(2), 71-99.

Sen, A. (2010). Desenvolvimento como liberdade. São Paulo: Companhia das Letras.

Silva, L. R. G. (2010). Sexualidade e orientação sexual na formação de professores: uma análise da política educacional. Tese de Doutorado, Universidade Estadual Paulista, Araraquara, São Paulo.

Toneli, M. J. F. (2004). Direitos sexuais e reprodutivos: algumas considerações para auxiliar a pensar o lugar da psicologia e sua produção teórica sobre a adolescência. Psicologia \& Sociedade 16(1), 151-160.

Ventura, M., \& Corrêia, S. (2006). Adolescência, sexualidade e reprodução: construções culturais, controvérsias normativas, alternativas interpretativas. Cad. Saúde Pública. 22(7), 1505-1509.

Villela, W. V., \& Doreto, D.T. (2006). Sobre a experiência sexual dos jovens. Cad. Saúde Pública 22(11), 2467-2472.

Yared, Y.B. (2011). A educação sexual na escola: tensões e prazeres na prática pedagógica de professores de ciências e biologia. Dissertação de Mestrado, Universidade do Planalto Catarinense, Lages, Santa Catarina.

Zanella, A.V., \& Molon, S. I. (2007). Psicologia (em) contextos de escolarização formal: das práticas de dominação à (re)invenção da vida. Contrapontos, 7(2), 255-268.

Recebido em: 23/08/2011

Reformulado em: 24/02/2012

Aprovado em: 02/04/2012

\section{Sobre os autores}

Marivete Gesser (marivete@yahoo.com.br)

Universidade Federal de Santa Catarina - UFSC, Centro de Filosofia e Ciências Humanas. Campus Universitário - Trindade - CEP 88.040-970. Florianópolis - Santa Catarina - Brasil.

Leandro Castro Oltramari (cord.denise@gmail.com)

Universidade Federal de Santa Catarina - UFSC, Centro de Filosofia e Ciências Humanas. Campus Universitário - Trindade - CEP 88.040-970. Florianópolis - Santa Catarina - Brasil.

Denise Cord (cord.denise@gmail.com)

Universidade Federal de Santa Catarina - UFSC, Centro de Filosofia e Ciências Humanas. Campus Universitário - Trindade - CEP 88.040-970. Florianópolis - Santa Catarina - Brasil. .

Adriano Henrique Nuernberg (adrianoh@cfh.ufsc.br)

Universidade Federal de Santa Catarina - UFSC, Centro de Filosofia e Ciências Humanas. Campus Universitário - Trindade - CEP 88.040-970. Florianópolis - Santa Catarina - Brasil. 